\title{
A rare case report of reversible acute kidney injury due to hyperuricemia alone
}

\author{
Yan Zhang ${ }^{1,2} \cdot$ Wei-Xiu Wang ${ }^{1} \cdot$ Xiao-Xiao Zhang $^{1} \cdot$ Man-Yu Zhang ${ }^{1} \cdot$ Ya-Ru Ren ${ }^{2} \cdot$ Ding-Wei Yang $^{1}$ (]
}

Received: 2 November 2020 / Accepted: 2 December 2020 / Published online: 3 January 2021

(c) The Author(s) 2021

\section{Editor,}

Acute uric acid nephropathy is one of the causes of acute kidney injury (AKI), which usually occurs in patients with tumor lysis syndrome and postoperative cardiopulmonary $[1,2]$. AKI due to hyperuricemia alone is rare. Here, we reported a patient who developed AKI due to elevated serum uric acid (UA) solely and recovered completely after treatment.

A 27-year-old male with a history of gout diagnosed 2 years ago was admitted for nausea, vomit and serum creatinine (Scr) increasing for 1 day with no significant past history and medical history. His eating habits were profound intake of purine-rich foods. Physical examination showed: temperature was $37.4{ }^{\circ} \mathrm{C}$, blood pressure was $140 / 93 \mathrm{mmHg}$, ankle edema, and no other abnormalities. Investigations revealed extremely elevated UA, Scr and blood urea nitrogen (BUN), which increased to 1123, 676 and 23.54, respectively, from reference values (reference range were $208-428 \mu \mathrm{mol} / \mathrm{L}, 61.9-114.9 \mu \mathrm{mol} / \mathrm{L}$ and $3.1-8.0 \mathrm{mmol} / \mathrm{L}$, respectively) and decreased UA in the urine of 1187.5 (reference range was $2400-5400 \mu \mathrm{mol} / 24 \mathrm{~h}$ ). The urine UAto-creatinine ratio was 1.76 and a large number of uric acid crystals were found in the urinary sediment, which was consistent with acute uric acid nephropathy [3]. Serum cystatin $\mathrm{C}$ and serum $\beta_{2}$ microglobulin increased mildly. Hepatitis $B$ virus (HBV) surface antigen, HBV e-antigen and HBV core antibody were positive in the serum. Hemodialysis was used to remove metabolic wastes. Febuxostat, methylprednisolone and tenofovir alafenamide fumarate were also added. One day after treatment, levels of serum UA,

Ding-Wei Yang

dwyang2016@126.com; dxyang0072003@163.com

1 Division of Nephrology, Department of Internal Medicine, Tianjin Hospital, No. 406 Jiefang South Road, Hexi, Tianjin 300211, China

2 Graduate School, Tianjin Medical University, Tianjin, China
Scr and BUN quickly corrected to $671 \mu \mathrm{mol} / \mathrm{L}, 537 \mu \mathrm{mol} / \mathrm{L}$ and $17.26 \mathrm{mmol} / \mathrm{L}$ significantly with clinical symptoms resolved. Maintenance therapy with hemodialysis was used again on day 3. After 5 days' treatment, levels of serum UA, Scr and BUN were decreased to $461 \mu \mathrm{mol} / \mathrm{L}, 163 \mu \mathrm{mol} / \mathrm{L}$ and $9.76 \mathrm{mmol} / \mathrm{L}$, respectively, with sustained urine volume being $1500-2500 \mathrm{~mL}$. On day 7 , he was discharged with the levels of Scr and BUN normal $(96 \mu \mathrm{mol} / \mathrm{L}$ and $7.8 \mathrm{mmol} / \mathrm{L}$, respectively) and serum UA being $440 \mu \mathrm{mol} / \mathrm{L}$.

AKI can be caused by hyperuricemia alone. A highpurine diet, increased purine metabolism and excessive alcohol consumption could result in increasing UA production rapidly [4]. Uric acid crystal-induced tubular obstruction is associated with AKI [5, 6]. Oxidative stress, activation of renin-angiotensin system and inflammasome pathway also contribute to AKI [5-7]. Hyperuricemia-induced AKI always presents with elevated serum UA levels (typically $>10-15 \mathrm{mg} / \mathrm{dL}$ ), presence of uric acid crystals in the renal sediment, and an elevated urine UA-to-creatinine ratio of $>1$ [3]. The pathologic features of acute uric acid nephropathy are reversible. Renal function is expected to be completely restored if hemodialysis is initiated in time to rapidly reduce serum UA and Scr. Febuxostat and corticosteroids are considered to be efficacious in serum UA lowering and protecting the renal function [8-10].

In conclusion, this was a unique case of AKI caused by extremely high increase in serum UA level alone. The pathologic features of hyperuricemia-induced AKI are reversible. With timely recognition and management, the renal function can be restored completely.

Author contributions DWY conceived and performed the treatment. $\mathrm{YZ}$ and WXW assisted in the preparation of the manuscript. YZ, WXW, XXZ, Man-Yu Zhang and YRR were involved with patient data collection and acquisition. YZ drafted the initial manuscript and all other authors critically reviewed and revised the manuscript. All authors read and approved the final version of the manuscript. 


\section{Compliance with ethical standards}

Conflict of interest We declare no financial support or relationships that may pose conflict of interest.

Informed consent The patient has given written consent to publish his personal and medical information for the publication of the case report.

Research involving human participants and/or animals Authors declare this work does not include research involving human participants or animals.

Open Access This article is licensed under a Creative Commons Attribution 4.0 International License, which permits use, sharing, adaptation, distribution and reproduction in any medium or format, as long as you give appropriate credit to the original author(s) and the source, provide a link to the Creative Commons licence, and indicate if changes were made. The images or other third party material in this article are included in the article's Creative Commons licence, unless indicated otherwise in a credit line to the material. If material is not included in the article's Creative Commons licence and your intended use is not permitted by statutory regulation or exceeds the permitted use, you will need to obtain permission directly from the copyright holder. To view a copy of this licence, visit http://creativecommons.org/licenses/by/4.0/.

\section{References}

1. Yoshitaka I, Yoshitsugu T, Atsushi T et al (2016) Hyperuricemiainduced inflammasome and kidney diseases [J]. NDT 31:890-896

2. Yohan P, Byung HC, Cheol WP et al (2020) Acute kidney injury with extreme hyperuricemia after antithymocyte globulin treatment in a kidney transplant recipient with underlying aplastic anemia: a case report [J]. BMC Nephrology 21:251-255

3. Kelton J, Kelley WN, Holmes EW (1978) A rapid method for the diagnosis of acute uric acid nephropathy [J]. JAMA Intern Med 138(4):612-615

4. Fathallah-Shaykh SA, Cramer MT (2014) Uric acid and the kidney [J]. Pediatr Nephrol 29(6):999-1008

5. Su HY, Yang C, Liang D et al (2020) Research advances in the mechanisms of hyperuricemia-induced renal injury [J]. Biomed Res Int. https://doi.org/10.1155/2020/5817348

6. Yang L, Chang B, Guo Y et al (2019) The role of oxidative stressmediated apoptosis in the pathogenesis of uric acid nephropathy [J]. Ren Fail 41(1):616-622

7. Min WK, Ho JC, Kwon WJ et al (2019) Hyperuricemia is associated with acute kidney injury and all-cause mortality in hospitalized patients [J]. APSN 24:718-724

8. Zhang X, Wan DP, Yang GS et al (2019) Febuxostat is superior to allopurinol in delaying the progression of renal impairment in patients with chronic kidney disease and hyperuricemia [J]. Int Urol Nephrol 51(12):2273-2283

9. Sircar D, Chatterjee S, Waikhom R et al (2015) Efficacy of febuxostat for slowing the GFR decline in patients with CKD and asymptomatic hyperuricemia: a 6 month, double-blind, randomized, placebo-controlled trial [J]. Am J Kidney Dis 66:945-950

10. Claudio P, Francesco L (2018) Glucocorticoids in the treatment of glomerular diseases: pitfalls and pearls [J]. Clin J Am Soc Nephrol $13: 815-822$

Publisher's Note Springer Nature remains neutral with regard to jurisdictional claims in published maps and institutional affiliations. 